\title{
Flood Hazard Mapping in Lower Reach of Kelani River
}

\author{
I. P. Ajith Gunasekara
}

\begin{abstract}
After the Tsunami, disaster management strategies have undergone rapid changes. Flood hazard mapping has, particularly, been realized as one of foremost tasks to be accomplished in support of disaster management and sustainable development. As a pioneering effort, the lower reach of Kelani River which covers the islandis capital, Colombo, and two densely populated districts of the country. Colombo and Gampaha districts which are frequently and considerably affected by flood events, were chosen for flood hazard mapping together with the part of the slightly affected adjoining Kegalle district. The study covers all most all the potential flood area in Kelani river. The objective of the study were, 1) Prepare flood depth and flood extend maps for different return periods, 2) Identify flood management and flood-disaster mitigation strategies.
\end{abstract}

This exercise comprises four basic steps,1) Generation of Terrain model in the study area to work in Arc View, 2) Determination of flood discharges for different return periods, 3) Flow profile generation using Hydrodynamic model; HEC RAS and 4) Generation of flood area and depth maps by exporting the hydrodynamic model results to ArcView. The one dimensional steady flow module of HEC-RAS Software was utilized for water surface profile, flood area, and flood depth calculations. The requisite geo-spatial modeling of the flood plain was carried out conveniently by implementing HEC-GeoRAS module in the ArcView environment using a triangular irregular network (TIN) model. Peak flows associated with selected return periods were obtained from a frequency analysis and the calibration run was executed simulating the 50 year return period flood event.

Comparison of field records corresponding to the above event of 1989 indicates that the modeling of flow and terrain conditions is very successful. Accordingly, a set of flood hazard maps associated with 10 year, 20 year, and 50 year return period events. Results show that the study area would be subjected to flood encroachments of 60,77 , and 94 square kilometers for events with return periods of 10 years, 20 years, and 50 years respectively. Model results were compared and verified against the records available in the Irrigation Department in addition to the field verification.

\section{Introduction}

Sri Lanka is located in the Indian ocean between the bay of Bengal and Gulf of Mannar, between northern latitudes of 5051 ' to 9051 ' and east longitudes of $79040^{\prime}$ to $81055^{\prime}$. It occupies an area of nearly $65525 \mathrm{sq} . \mathrm{km}$.

The water resources map of the country prepared in 1959 identified 103 river basins of which about 10 rivers are considered as major. Among these major rivers, Kalu, Kelani, Gin, Nilwala and Mahaweli are vulnerable to floods. Of the factors that are conducive to the creation of flood problems, one of the principal causes is encroachment by man on the flood plains of river basins.

Floods in Sri Lanka are mainly due to excessive rainfall received during monsoons and received as a result of development of low-pressure in the Bay of Bengal. Floods are directly related to rainfall and therefore a proper understanding about the distribution of rainfall becomes important. The rainfall distribution in Sri Lanka is subject to spatial and temporal variations leading to distinct patterns of seasonality, regionality and inter-annual variability in the climate. The average annual rainfall ranges from around $800 \mathrm{~mm}$ to over $5000 \mathrm{~mm}$.

Recent past several flash floods occur, without giving much time for evacuation, and

\footnotetext{
Eng. I.P.Ajith Gunasekara, BSc Eng. in Civil Engineering from the University of Moratuwain 1993. He completed PG Diploma on Water Resources Engineering \& Management in year 2000 from Universityof Moratuwa. MIE (Sri Lanka).

At present he works as the Chief Irrigation Engineer in the Hydrology Division of the Irrigation department.
} 
diminished within two to three days. So far, in 2008, there are three flood events one in $29^{\text {th }}$ of April, 30th of May and other in $19^{\text {th }}$ of July for Kelani, Kalu and Gin basins.

Floods in Kelani river are important due to its outfall being near the capital city of Colombo. When the flood levels of Kelani are in between $5.0 \mathrm{ft}$. and $7.0 \mathrm{ft}$. at the Nagalagam (Colombo) gauge, they are within the limits of minor floods. When the level exceeds $7.0 \mathrm{ft}$. the flood is defined as a major flood and when it exceeds $9.0 \mathrm{ft}$. the flood is considered to be dangerous.

Among the non-structural flood mitigation methods, Kelani is one river, where there has been a flood forecasting system. Forecasting of water levels in the river is done by means of five upstream gauges. A scheme of organization and standing orders are available to facilitate the coordination among several institutions during a flood. This scheme of organization and standing orders prepared in 1968 and updated by the Irrigation Department in 1993, can be considered as a comprehensive study to provide a detailed mitigation plan for the city of Colombo.

Flood was identified as most common and hazades natural event in Sri Lanka, proved in history and obvious as the country's topography and location.

Flood area mapping in the lower reach of the Kelani river basin became a top necessity with frequent floods in Kelani River

\section{Study Area}

Kelani River is the second largest in the country which originates in the central hills and flows mainly to the West till it meets the sea at the northern boundary of the Colombo city. River basin is entirely located in the wet zone up to an extent of 2230sq.km. Its average annual rainfall is about $2400 \mathrm{~mm}$.

The river basin comprises of two distinct types of topography, mountainous upper region and flat coastal line. Approximately two-thirds of the entire catchment represents the mountainous region, where the peaks and ridges rise above $2000 \mathrm{~m}$ MSL contour. Valley slope is very steep and the mountain streams are characterized by waterfalls and rapids.
Vegetation in this region is mainly Tea, Rubber and grass. In many places exposed bed-rock can be seen.

On the contrary, the coastal plain is extremely flat with scattered low hills. The vegetation of this region is a mixture of Rubber, Coconut, Paddy, Tea, marshy lands and grass. In the last $30 \mathrm{~km}$ the river bed slope flattens considerably, i.e. to an extent of 1:5000, and river valleys open out revealing wide flood plains.

With the knowledge of historical flood events occurred in the basin, lower reach of Kelani river is considered for flood mapping. It covers the flood plains from Glcncourse gauging station upto Nagalagam street gauging station in Colombo. Total length of the river in this section is about $55 \mathrm{~km}$. Study area covers three administrative districts. It occupies an area of $1200 \mathrm{sq} . \mathrm{km}$

\section{Objective}

The objectives of the study are:

\subsection{Preparation of Flood hazard maps for $10 \mathrm{yr}, 20 \mathrm{yr}$ and $50 \mathrm{yr}$ return periods.}

\subsection{Identification of flood management \& flood mitigation strategies.}

\section{Data Used}

Basically three categories of data were used for this exercise.

- Data necessary for the Hydro-dynamic modeling

- Data necessary for Digital Elevation Model (DEM/TIN).

- Socio-Economic information

\subsection{Data necessary for Hydro-Dynamic Modeling}

To execute the hydro-dynamic model from which the water surface profiles were to be generated, several parameters and variables are necessary. Many of the parameters are given in the model itself with an option to change in the calibration phase. Other than that some important data specific to the study are used as an input to the model. Some are used as inputs but not data, instead they are outcomes of the 
frequency analysis or Arc View done prior to performing the model. :

- Peak annual discharges (data).

- Rating curve of the U/S \& D/S gauging stations.(data).

- Cross sectional profiles of the river at regular intervals.(data)

- Cross sectional profiles of the flood plain including the river (result of Arc View)

- Flood discharges for different returperiods. (result of frequency analysis).

\subsection{Data necessary for TIN generation}

Terrain model is very important in this exercise. Accuracy of the flood hazard map greatly depends on the data used for the Triangular Irregular Network (TIN). Data used for TIN are:

- Contours(1:10,000 as of year 2000) \& Spot heights

- $\quad$ Stream network

\subsection{Analyzing the Results}

This part of the study intends to make the final output more informative whilst arriving at a final conclusion. They are:

- Road network

- Landuse map.

- Administrative boundaries

- Stream network.

- Cross sectional profiles of the river at regular intervals

\section{Methodology}

Methodology can be divided into four steps.i.e.

- Determination of discharges of different return periods

- Generation of Terrain model and incorporation of stream features to Terrain model

- Hydrodynamic modeling

- Flood area and flood depth mapping.

- Analyzing ofresults

\subsection{Generation of Terrain Model}

Terrain model is generated by means of the 1:10,000 topographic al digital data available in the Survey department. Areal Photographs and Land surveys are the Primary source of the Digital maps. Modifications are done to it after getting the cross-sectional data of the river from the Irrigation department.

\subsection{Determination of flood discharges for different return periods}

Statistical methods are used to get the flood discharges of the predetermined return periods. Hydrology division of the Irrigation department has been engaging in collecting stream flow data, precipitation data and other hydro-metrological data for nearly 100 years. As such annual peak discharges at the Glencourse gauging station for last 35 years were used in statistical analysis to determine the peak discharge.

There are several statistical methods available and used by various countries as their preference. In this study, three methods are adopted and they all give more or less the same results within a margin of $10 \%$. For the hydrodynamic modeling, the results of Gumbel Distribution were used and summary is tabulated below.

\subsection{Hydrodynamic modeling and water surface profile determination}

Water surface profile determination and subsequent flood-plain visualization is carried

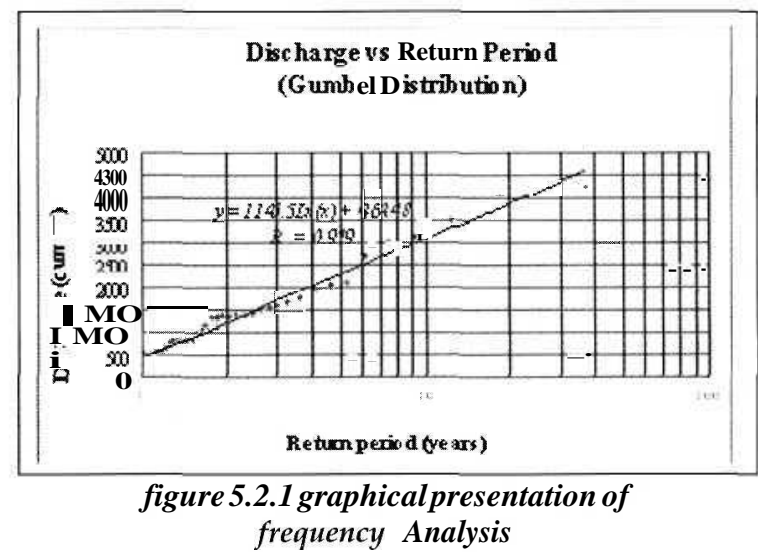

Table 5.2.1- Summary of frequency Analysis

\begin{tabular}{|c|c|c|c|}
\hline \multirow{2}{*}{$\begin{array}{c}\text { Return } \\
\text { Period Tr }\end{array}$} & \multicolumn{3}{|c|}{ Discharge $\left(\mathrm{m}^{3} / \mathrm{sec}\right)$} \\
\cline { 2 - 4 } & Lognormal & Pearson & Gumbel \\
\hline 10 & 2755 & 2799 & 3128 \\
20 & 3629 & 3839 & 3990 \\
50 & 4336 & 4743 & 4630 \\
\hline
\end{tabular}


out using one-dimensional numerical model developed by Hydrological Engineering Center of US Army Corps, commonly known as HEC-RAS. HEC-GeoRAS, an extention compatible with ArcView is used as the interface between Hydrodynamic Model and the Graphical software.

HEC-GeoRAS is capable of performing a set of step-by-step operations which allows the preparation of Geometric Data for importing into HEC-RAS and processes simulation results exported from HEC-RAS in to Arc View.

To execute the Hydrodynamic Model, Geometric data of the flood plain and stream are abstracted from the terrain elevation model. Water surface profiles, along the river reach under the study, for floods of three identified return periods are computed with sub-critical flow simulation. Finally Export file was created in HEC RAS to work with the Digital Elevation Model in Arc-View.

\subsection{Flood area and flood depth mapping}

Water profiles generated in HEC-RAS is exported in to the Arcview platform and the inundation areas and flood depths are visualized on the terrain model. Digital data of important features such as roads, buildings, cultivation, etc. are superimposed on to the Digital Elevation Model. Finally the flood depths are reclassified to suit preferred classification and the relevant details such as area according to Districts, No. of buildings inundated, etc. are calculated

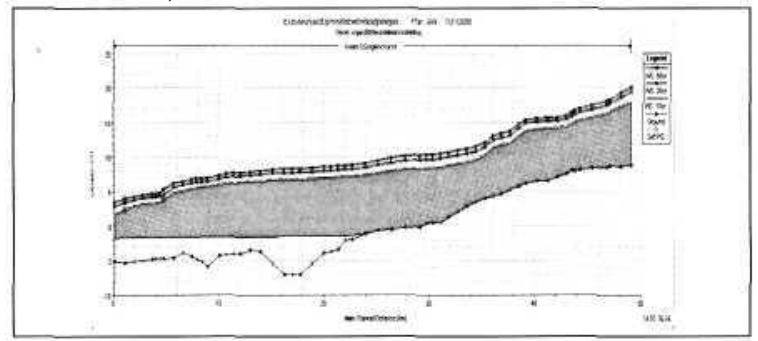

Figure 5.3.1 water surface profiles for 10year, 20 year and 50 year return periods

Table 6.1 - Total area of inundation in sq. $\mathrm{km}$ for different return periods

\begin{tabular}{|c|c|c|c|c|c|}
\hline & \multicolumn{4}{|c|}{ Flood depth (m) } & Total \\
\hline & $<1$ & $1-3$ & $3-5$ & $>5$ & \\
\hline 10 & 19 & 29 & 10 & 5 & 63 \\
\hline 20 & 20 & 40 & 11 & 6 & 77 \\
\hline 50 & 24 & 41 & 19 & 10 & 94 \\
\hline
\end{tabular}

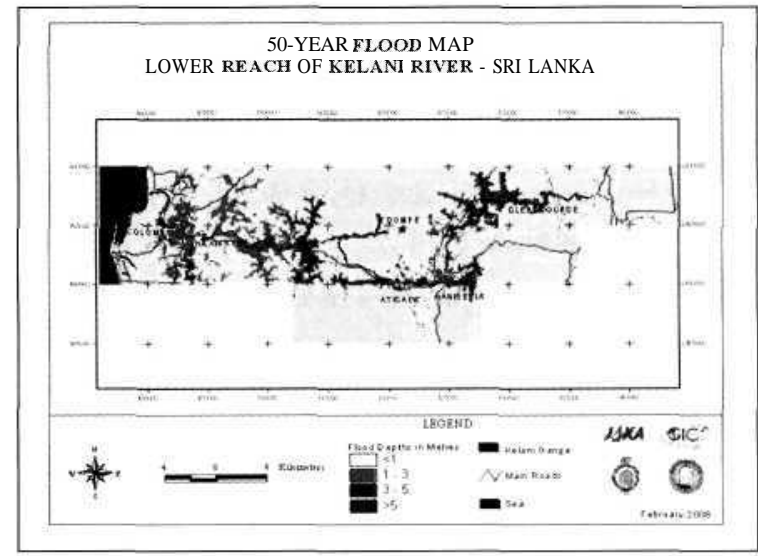

Figure 6.1 Flood map of 50-year return periodflood

\subsection{Analyzing of results}

The results obtained after the above steps are verified against the actual data. Historical records as well as the geographical data collected in field inspections and other information received from the people of the area, etc. are used in verifying the results. Until the results agree with the field records the

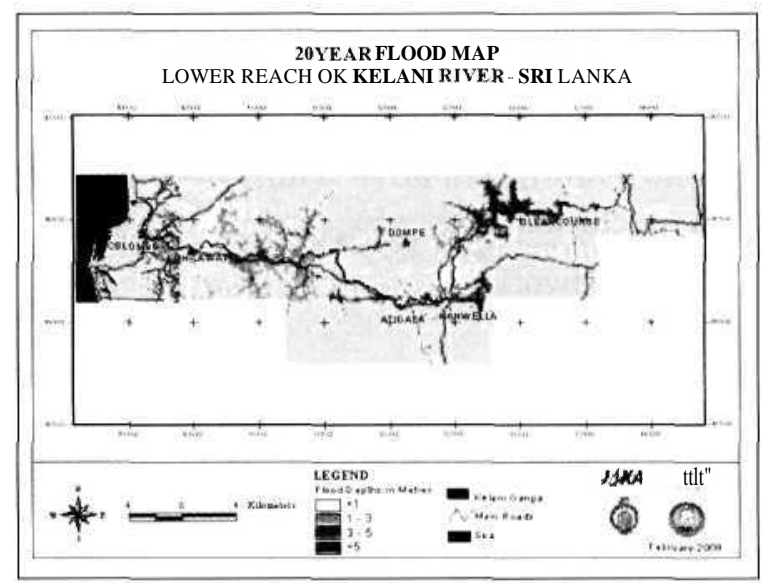

figure 6.2 Flood map of 20-year return periodflood.

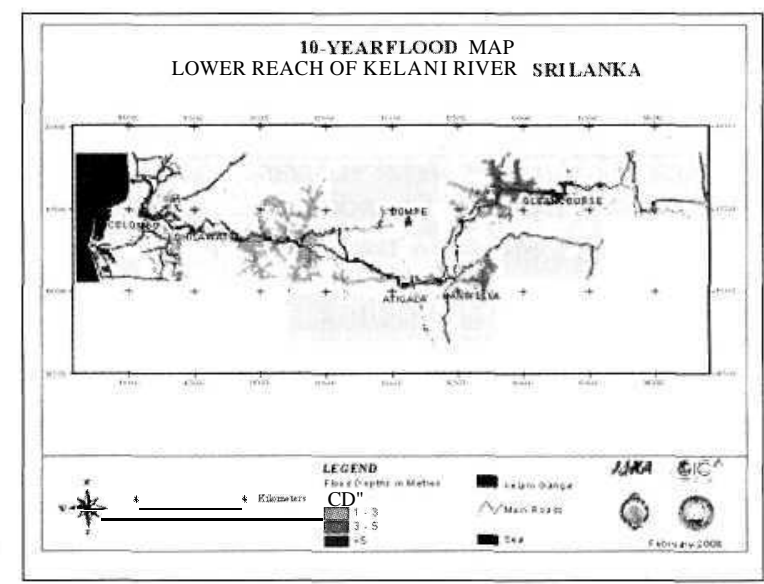

Figure 6.3 Flood map of 10-year return periodflood. 
Table 6.2 - Total No. of buildings affected indifferent return periods in District basis.

\begin{tabular}{|c|c|c|c|c|}
\hline \multirow{2}{*}{$\begin{array}{c}\text { Return } \\
\text { Period } \\
(\text { yrs ) }\end{array}$} & \multicolumn{3}{|c|}{ District } & \multirow[t]{2}{*}{ Total } \\
\hline & Colombo & Gampaha & Kegalle & \\
\hline 10 & 5421 & 3589 & 0 & 9010 \\
\hline 20 & 8487 & 5574 & 3 & 14064 \\
\hline 50 & 10378 & 6620 & 7 & 17005 \\
\hline
\end{tabular}

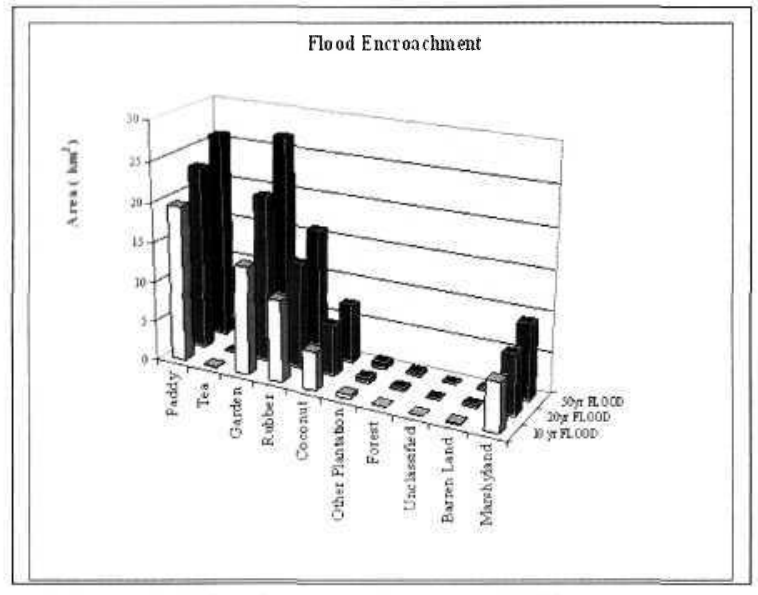

Figure 6.4 Flood encroachments of different return periods ( Colombo, Gampaha, Kegalle Districts)

Hydro-Dynamic Model parameters are adjusted in the calibration phase and the final flood hazard maps are prepared.

\section{Results and Discussion}

One objective of the study is to prepare a set of flood hazard maps for the lower Kelani River basin. This is the direct outcome of the exercise.

Flood maps for three different return periods are developed accordingly. 50-year, 20-year and 10 -year return period flood maps are shown in next pages.

Identification of the flood mitigation \& flood management strategies are the other objective of this study. In fact it is the most important and valuable output. According to the topo sheets, some of the possible flood management strategies in the lower part of the Kelani Basin are development of Retarding Basins and the construction of Flood bunds. There are several upstream reservoirs which have already been constructed mainly for the Hydro-power generation in a cascade. This serves greatly in flood management in the downstream part too. But construction of such reservoirs under the current socio-economic condition is far away from the reality. Topographically also there are very limited opportunities.
Using the available topographical maps and the water surface profiles generated using the Hydro-Dynamic Model, it is possible to identify the locations for Retarding basins and Flood Bunds. But field inspection is really necessary together with this as the present ground condition, most probably, would be different from the survey maps. Satellite images also can be used for this by limiting the field inspections to the finer matters.

From the maps shown below and the other details such as Land-use the information important for the planners and other stake holders are abstracted and some of them are listed inhere.

\section{Conclusions and Recommendations}

In the study, it is considered only the lower reach of Kelani river which is good enough for flood mapping as the area affected in a flood is mostly restricted to this coverage according to the field experience of the author as well as the historical records. It is proven even by the results of the study as the number of houses going to be affected in 50-year flood in Kegalle District, located in the up stream of the study area, is negligible when compared to the other districts and hence the area selected seems matching with the requirement. But in preparing the terrain model some essential areas in Colombo and Gampha districts could not be included, due to restrictions of time as there were some clarifications to be done. However that is less than $10 \%$ of the total area, I hope to include the rest of the omitted area and produce the new set of maps for the whole study area with more information

The aerial-photographs and spot heights used in generating the Terrain model are from year 2000. Most probably there can be changes in the terrain mainly due to development activities of various parties including the Government. Only the river cross sections were adjusted to suit to the actual values as in year 2007 using the land leveling done by the Irrigation department. For accurate results updated terrain data and landuse data are essential. It is a limitation that individuals can't overcome, but only the decision makers who are supposed to use this kind of results should take prompt actions to take care of such a problem. 
Further it is easy to verify the produced maps in the field in detail, more than what was done in the study, and can be adjusted if there is any drastic variation probably due to changes in land-use or terrain. Current practice of flood mapping in hydrology division, post-flood field data collection with GPS instrument, collection of information from people and leveling instruments, can be of great use for this kind of verification. It should also be noted that field data collection and preparation of a flood maps is a tedious process which consumes manpower beyond the manageable limits considering the limited resources and the assignments undertaken by the hydrology division. In contrast, verification is far easier as the area is demarcated and even the coordinates are available for easy access. . A microwave image of the study area during the flood season definitely would have been very useful in the flood extent verification, which unfortunately was not available during the study, as an option to time and human constraints. Use of modern technology for verification would be more attractive even for the users

\section{Acknowledgments}

First I have no hesitation in thanking Japan Aerospace Exploration Agency (JAXA) under which I had this research work conducted at Geoinformatics center, Asian Institute of Technology in Bangkok Thailand.
I am really grateful to Dr. Lal Samarakoon and Dr. Manzul K. Hazarika for allowing us to conduct this training and Workshop on Application of Remote Sensing and GIS.

Next I must thank to Ms. P.P. Liyanage of Survey Department for preparing the DEM for me, wich the study could not have been performed. She also contributed very much in preparing the Land-Use map, river network, etc.

The great encouragement given and the facilities provided by the Surveyor General Mr.B.J.P.Mendis, Director of Irrigation (Specialized services \& Training) Eng. P. C. Senaratne, Deputy Surveyor General Mrs. A. L. S. C. Perera, Deputy Director (Hydrology) Eng. Miss. P.P.G. Dias, Snr. Superintendent of surveyors Mr. S. Sivanandarajah are highly coppreciated and played a keg role in achievement of this study and I am grateful to all of them.

\section{References}

1. Presentation to the Regional Consultative Meeting for Disaster Management in December 1996 - Sri Lanka "flood mitigation in Sri Lanka", G.T.Dharmasena, Deputy Director - Irrigation Department.

2. Floods in Kelani Ganga, G.T.Dharmasena, Deputy Director-Irrigation Department. 